\title{
Adoption of a Social Learning Platform in Higher Education: An Extended UTAUT Model Implementation
}

\author{
Hager Khechine \\ Laval University \\ Hager.Khechine@ sio.ulaval.ca
}

\author{
Marc Augier \\ IPAG \\ marc.augier@ipag.fr
}

\begin{abstract}
The aim of this research is to investigate the factors influencing the adoption of a social learning platform called PairForm using an extended unified theory of acceptance and use of technology (UTAUT) model. The UTAUT extension consists of adding three personal characteristics of students, namely autonomy, anxiety, and attitude. Data obtained from 85 Frenchspeaking students and 14 English-speaking students at the Skema Business School, a higher education institution, showed good reliability coefficients and satisfactory convergent and discriminant validities. Regression analysis suggests the facilitating conditions construct is the main predictor of behavioral intention to use and behavioral use of PairForm. Attitude is the only personal characteristic that explains behavioral intention to use. In the light of these results, we propose recommendations that, if implemented, could create more favorable conditions for the use of social learning technologies.
\end{abstract}

\section{Introduction}

"Our students have changed radically. Today's students are no longer the people our educational system was designed to teach." This is what Prensky [1] said in 2001 to explain the decline of education in the United States. Since that time, technology has evolved drastically and has changed the way students think, behave, and process information.

The use of technology in higher education has caught the attention of many researchers. For instance, in 2008, the Economist Intelligence Unit [2] conducted a large survey in the United States to examine how technology would shape learning. The results of this study showed that the technologies expected to improve academics were online-collaboration tools, software that supports individually-paced learning, and learning management systems (LMSs). Although this prediction was correct, the study's prediction that Web
2.0 technologies such as wikis, instant messaging, and social networking would decline did not occur. Social networking has invaded the Internet, and most postsecondary institutions are aware of the potential of the Web as a tool for virtual collaboration and enhanced student engagement [3]. The days where learning is considered an individual activity where the learner relies on the content delivered by an expert are behind us. As the times have changed, teaching and learning approaches need to adapt to the new generation of students that lives on Web 2.0 every day. This adaptation goes through social learning, which considers social media as part of learning.

Social learning is a concept that emerged from social learning theory, developed by Canadian psychologist Albert Bandura in the early 1960s. He argues that most of what we learn derives from our physical social environment. We learn by observing parents, classmates, and colleagues [4]. This theory was extended to the virtual world by substituting the physical social environment for the virtual one using Web 2.0 technologies [5]. Among the Web 2.0 tools, research has reported the successful use of blogs; wikis; social bookmarking tools; microblogging tools, such as Twitter; and media-sharing tools, such as YouTube, Picasa, and SlideShare, in educational settings [6].

Most LMSs use external social learning tools (e.g., Web 2.0 technologies), however, LMSs with a social learning component are scarce [7]. Among them, PairForm is a digital LMS that allows learning communities to interact without resorting to external Web 2.0 tools. To our knowledge, no study has investigated the factors influencing the adoption of a LMS in which social learning tools are embedded. Thus, the main objective of this study was to identify the determinants of the behavioral intention to use PairForm and its effective use by students. We conducted the research at the Skema Business School for an in-class course where technology use is not compulsory. In addition to the main determinants of technology adoption (performance expectancy, effort 
expectancy, social influence, and facilitating conditions), we also assessed the role of three personal characteristics (autonomy, anxiety, and attitude) on behavioral intention to use and behavioral use. Previous research has affirmed that the propensity of students to use a certain kind of technology is dependent on their personal characteristics [8, 9]. More globally, we deem it relevant to study the acceptance and the adoption of this kind of technology for two reasons. First, we are convinced that the use of social learning technologies will become more popular in higher education over the coming decades because actual and future students are considered Web 2.0 "natives." Second, literature in management information systems considers acceptance and adoption to be a sine qua non to the success and the efficiency of any technology [10]. Therefore, we argue that understanding factors influencing the use of PairForm can help ensure its effective deployment and consequently enhance student productivity.

The paper is organized into seven main sections. Next, we present the literature about social learning and the PairForm technology. Then, we describe the research variables, model, and hypotheses. In the research design section, we explain the study's setting and the procedure we used to collect data. We detail and interpret the study results in the fifth section. In the conclusion, we highlight the theoretical and practical contributions of the research and discuss research limits and future research.

\section{Literature review}

Social learning is a concept that existed far before the advent of information technology. However, the growth of social media has revived interest in social learning by instructors.

\subsection{Social learning}

Two decades ago, e-learning began assuming a significant place in many universities due to the various advantages it offered, such as allowing geographically-dispersed students to enroll in online courses [11]. Detractors of this course delivery mode considered it to be a trend that would fade with time. However, e-learning evolved and adopted a variety of forms to accommodate students' needs. For instance, to avoid seclusion, online courses were transformed into blended ones by combining e-learning techniques with traditional face-to-face learning approaches. Within blended learning, social interaction can be achieved physically in class or virtually online.

Instructors who offered face-to-face in-class courses realized the contribution of online social interactions to the success of blended courses. Coping with a student generation that is always connected to social media, these instructors strived to adopt social learning in face-to-face courses, as done in blended learning. According to Popescu and Cioiu [6], instructors have to adapt traditional teaching methods to respond to the needs of what is called the "Internet generation." This can be done by fostering online social learning.

According to social learning theory, interaction makes people share tacit skills and knowledge [11]. The result of this interaction is considered an extension of learning outside the classroom because each student learns from others' backgrounds and experiences and from observing each other. For a better learning experience, knowledge is not only transmitted in faceto-face courses, but also constructed by means of the collaborative efforts of the learners. This principle corresponds to the socio-constructive approach to which modern educational theories adhere [6]. In this approach, knowledge is constructed through the interaction of each student, not only with the instructor, but with the other students. As with contribution-based pedagogies, students are simultaneously content consumers and content generators or co-creators who share knowledge with classmates [6].

Social media or Web 2.0 systems are the most popular tools for achieving active and collaborative learning experiences [12]. Many studies report that these tools contribute to enhancing students' satisfaction, knowledge, and learning [6]. Among these tools, students use social bookmarking applications (e.g., reddit.com), blogs, wikis, social networking systems (e.g., Facebook and LinkedIn), social content applications (e.g., Flikr and YouTube), synchronous communication technologies (e.g, Skype and Adobe Connect), and virtual world applications (e.g., Second Life) [12]. These tools are outside most of the LMSs. Instructors have to work hard to make students adopt them if their pedagogy relies on social learning. However, a better use of social learning technologies could be achieved if these technologies were part of the course LMS.

\subsection{PairForm}

PairForm is a content development application based on the Scenari Open Source project [13]. It is made of several tools that support the development of learning content. The modules produced with PairForm can be imported in a LMS platform to extend the LMS functionalities. There is also the possibility to use PairForm modules directly. In this situation, PairForm can be seen as a LMS platform itself. A free app available from the Apple Store for iOS smart devices 
permits PairForm content to be used on a mobile device. It is considered to be the first LMS that has a "social network" embedded in it. PairForm was designed and developed by a young technology enterprise by the same name. This start-up, which specializes in digital education, was created at the Institut Mines-Telecom Atlantic laboratory in France.

PairForm is a peer-training tool for accessing knowledge content and interacting with a knowledgebased community. For instance, PairForm allows users to upload documents and to share them with others, to co-write documents in a manner similar to in Google Docs, to chat inside each document, to chat inside the training modules, and to tag individual learners' contributions. A crucial functionality of PairForm consists in allowing the user to comment or ask a question directly in a document by marking the concerned word or sentence. With this feature, PairForm, unlike online forums, avoids creating distance between the text and the reaction. Indeed, the discussion thread can be built inside the document, which removes the hurdle between information access and understanding. These examples show how PairForm makes it possible for communities to interact at the heart of the online training material. In addition to PairForm's advantages, its creators assert that this social learning tool contributes to creating communities of practice, matching people with a variety of profiles, and promoting collective intelligence [14].

Recent research has focused on studying the use of social media for boosting higher education. For instance, the authors of [15] suggested integrating YouTube videos into courses because such videos can help students seek information and learn better. A recent study concluded that students would like to use Facebook groups, YouTube channels, wikis, and forums for their learning [16]. To our knowledge, no research has studied the use of social media tools that are part of a LMS such as PairForm.

\section{Research model and hypotheses}

In this section, we define the research variables and the hypotheses to be tested. The research model integrates personal characteristics of students with the main variables of the unified theory of acceptance and use of technology (UTAUT).

\subsection{Research variables}

In 2003, the UTAUT model was designed to synthesize previous theories on technology acceptance by users. This model allowed researchers to obtain a more exhaustive prediction of users' behavior than previous models [17]. UTAUT is considered by many authors to be the best predictive model in the acceptance literature [18]. Research in education has applied the UTAUT model to identify the determinants of students' acceptance and use of various technologies in many countries [19]. To adapt the original UTAUT model to the educational context, many variables have been added to ensure a better understanding of technology acceptance by students. Some of these variables are the perceived risk of decisions [20], autonomy [8], self-efficacy, attitude, anxiety [21], and personality traits [22].

For this research, we adopted the original UTAUT model, to which we added three personal characteristics of student as determinants of behavioral intention to use and behavioral use for the social learning system, PairForm. The latent variables of our research model are performance expectancy (PE: selfperception of the students about their performance in the course when using the learning system); effort expectancy (EE: ease of using the learning system); social influence (SI: opinion of the other students, teachers, friends, classmates, and family members about using the learning system); facilitating conditions (FC: human, organizational, and technical support for using the learning system); behavioral intention to use (BI: willingness to use the learning system); anxiety (degree of fear or discomfort with using the learning system); attitude (students' feelings about the learning system); and autonomy (independence of students of external control) [23].

\subsection{Hypotheses and research model}

The meta-analysis of Khechine et al. [17] confirmed the relevance of testing the direct relationships between the main variables of the original UTAUT model. Venkatesh et al. [23] considered the inclusion of the moderating variables gender, age, and experience to be important for controlling their effects on the main relationships of the UTAUT model. The variable voluntariness of use, which plays a moderating role in the original UTAUT model, was dropped from the current model because the use of PairForm is a voluntary decision. We also deem it relevant to assess the role of sutdents' personal characteristics, such as autonomy, anxiety, and attitude, in relation to the adoption of social learning technologies. The relationships between the original UTAUT variables and the possible effects of the personal characteristics on the dependent variables are depicted in Figure 1. 


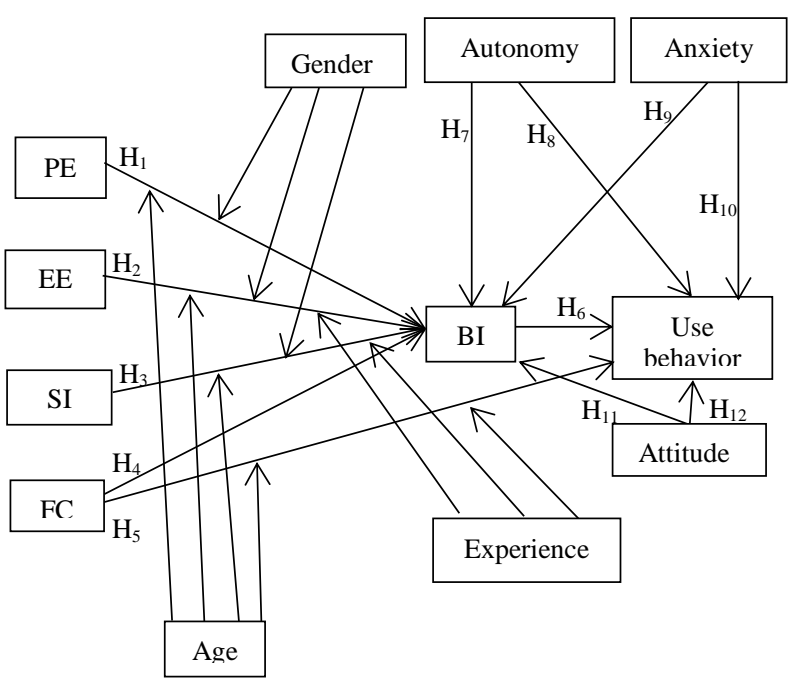

Figure 1. Research model

The robustness of the relationship between performance expectancy and behavioral intention was confirmed in previous research [17]. Users are eager to adopt a system because they perceive productivity, efficiency, and effectiveness returns. Therefore, we hypothesize that students who expect to better perform while using the social system PairForm would be more inclined to use the system. Thus, we propose;

$\boldsymbol{H}_{1}$ : The relationship between performance expectancy and the behavioral intention to use PairForm is significant and positive.

In the original UTAUT model, age and gender play a moderating role in the relationship between performance expectancy and behavioral intention. The positive relationship between these two variables was stronger for younger men [19, 24]. Therefore, for the PairForm system, we propose the following hypothesis:

$\boldsymbol{H}_{1 \boldsymbol{a}}:$ The relationship between performance expectancy and the behavioral intention to use PairForm is moderated by gender and age, such that the effect is stronger for young male students.

The relationship between effort expectancy and behavioral intention has often been found to be significant and positive [17]. The principle that supports this relationship is that easy-to-use systems make users more willing to adopt them. Accordingly, keeping in mind that most of the e-learning systems on the market, including PairForm, are user-friendly, we propose the following hypothesis:

$\boldsymbol{H}_{2}$ : The relationship between effort expectancy and behavioral intention to use PairForm is significant and positive.

Previous research has confirmed in various settings that effort expectancy has a stronger effect on the behavioral intention for older [23] women users [24] who have little experience with technology [23]. For PairForm, we propose similar moderating effects for gender, age, and experience in the following hypothesis:

$\boldsymbol{H}_{2 a}$ : The relationship between effort expectancy and the behavioral intention to use PairForm is moderated by gender, age, and experience, such that the effect is stronger for older female students who have less experience with computers.

Khechine et al. [19] confirmed the effect of social influence on the intention of webinar use in a voluntary context. We argue the intention to use PairForm will be influenced by others' opinions, especially those of other students, classmates, teachers, friends, and family members. Therefore, we propose the following hypothesis:

$\boldsymbol{H}_{3}$ : The relationship between social influence and the behavioral intention to use PairForm is significant and positive.

According to Venkatesh et al. [23], age, gender, and experience moderate the effect of social influence on behavioral intention such that the effects are more salient for older women at the early stages of use. We posit that the context of the use of PairForm is similar to the setting of Venkatesh et al. [23], as reflected in the following hypothesis:

$\boldsymbol{H}_{3 a}$ : The relationship between social influence and the behavioral intention to use PairForm is moderated by gender, age, and experience, such that the effect is stronger for older female students who have less experience with computers.

The relationship between facilitating conditions and behavioral intention has been found to be significant and positive in the UTAUT2 model [25]. In the context of PairForm use, we consider students to be consumers (as in the UTAUT2 setting) who have easy access to information about the technology via the internet and smart devices. Moreover, facilitating conditions variable has been shown to be a determinant of use behavior [23]. Thus, we propose the following hypotheses:

$\boldsymbol{H}_{4}$ : The relationship between facilitating conditions and the behavioral intention to use PairForm is significant and positive.

$\boldsymbol{H}_{5}$ : The relationship between facilitating conditions and the use behavior of PairForm is significant and positive.

According to research in psychology, older workers need more assistance and help in their jobs [26]. Moreover, the dependence of users on external support is lowered by the greater experience acquired with technology [27]. Relying on these arguments, Venkatesh et al. [23] considered age and experience to be moderators of the relationship between facilitating 
conditions and use behavior. For PairForm use, we propose the following hypothesis:

$\boldsymbol{H}_{5 a}$ : The relationship between facilitating conditions and the use behavior of PairForm is moderated by age and experience, such that the effect is stronger for older students who have less experience with computers.

Technology adoption models support the idea that a user's intention is often an antecedent of action. Khechine et al. [17] confirmed the positive relationship between behavioral intention and use through a metaanalysis of the UTAUT research. Because the use of PairForm is a voluntary act, the sixth hypothesis that we propose is:

$\boldsymbol{H}_{6}$ : The relationship between behavioral intention and the use behavior of PairForm is significant and positive.

We deem it relevant to evaluate the direct effect of autonomy on the intention to use PairForm because the feelings of responsibility and self-control can make students comfortable with technology and more willing to use it. As Johns [28] asserted, behavior is constrained by limited autonomy, and we can posit that autonomy may stimulate behavior in the context of PairForm use. The two following hypotheses reflect these relationships:

$\boldsymbol{H}_{7}$ : The relationship between autonomy and the behavioral intention to use PairForm is significant and positive.

$\boldsymbol{H}_{8}$ : The relationship between autonomy and use behavior of PairForm is significant and positive.

Powel's [29] meta-analysis confirmed the influence of anxiety on individual acceptance of information technologies. Beaudry and Pinsonneault [30] explained this influence by asserting that anxiety leads users to physically evade the stressor [18] and to look for exit options, such as avoiding the use of a new technology [31]. Considering these arguments, we propose the following hypotheses:

$\boldsymbol{H}_{9}$ : The relationship between anxiety and the behavioral intention to use PairForm is significant and negative.

$\boldsymbol{H}_{10}$ : The relationship between anxiety and use behavior of PairForm is significant and negative.

Previous acceptance theories, such as the technology acceptance model, asserted that a positive attitude toward a technology makes users more likely to adopt that technology than users with a negative attitude [32]. Even if Venkatesh et al. [23] suggested excluding attitude in the presence of performance expectancy and effect expectancy, we opt to keep attitude as a determinant of behavioral intention and use behavior because attitude measures the perception of pleasantness and not of performance or easiness. Thus, for PairForm use, we hypothesize:
$\boldsymbol{H}_{11}$ : The relationship between attitude and the behavioral intention to use PairForm is significant and positive.

$\boldsymbol{H}_{12}$ : The relationship between attitude and use behavior of PairForm is significant and positive.

\section{Research design}

The details of the study's setting and the questionnaire that we used to collect data are described in this section.

\subsection{Study setting}

This study was conducted on the various campuses of the Skema Business School (Lille, Paris, and Sophia Antipolis in France, Raleigh in the USA, Suzhou in China, and Belo Horizonte in Brazil). We asked undergraduate students enrolled in a compulsory inclass course on information systems to participate to our study. Students were enrolled in many business concentrations, such as marketing, corporate finance, information systems, accounting, and luxury and fashion management. Whatever the location or the specialization, the course was taught in English, even though about $80 \%$ of the students were francophone. A different instructor on each campus taught the course, but the course owner (instructor with overall responsibility for the course) was based at the Sophia Antipolis campus in France. The course owner developed the e-learning content with the Scenari software, an open software solution that allows creating structured content and publishing documents (https://scenari.software/fr/). This content was available to all students via the School's LMS. Subsequently, the course owner wondered how the learning environment could be enhanced and decided on fostering social interaction between this very large and geographically-dispersed cohort. The course owner had already tested several solutions like Facebook and the open source social networking engine ELGG (https://elgg.org/), however, he discarded these solutions because of their lack of consistency between the content and the conversations that were on disparate platforms. In contrast, PairForm has the unique feature of connecting the existing online content to conversation. Thus, the course owner decided to give all students access to the PairForm system so they could not only share the same course content, but also communicate and collaborate directly on that content.

Data collection was done after course completion and lasted ten weeks. The first message was sent to the students enrolled in the course on different campuses by electronic mail to invite them to fill out the 
electronic questionnaire. Students' participation was voluntary, and two reminders were distributed over the weeks following the initial email.

\subsection{Questionnaire}

For data collection, we used an online questionnaire comprising 58 items in both French and English. Completing the questionnaire required nearly 20 minutes. The variables age, gender, campus, experience with a computer, in-class presence, and use behavior of PairForm were each measured with one item. The other variables comprised several items and were rated on a 7-point Likert-type scale (strongly disagree to strongly agree). From the original UTAUT questionnaire [23], we retained nine items for performance expectancy, three for effort expectancy, nine for social influence, seven for facilitating conditions, and three for behavioral intention, all of which we adapted to the specific settings of this study. The other 21 items allowed us to measure the personal characteristics of the students (five items for attitude, ten items for anxiety, and six items for autonomy), which we obtained from Fillion [33] and Venkatesh et al. [23].

\section{Results}

The presentation of the results begins with descriptive statistics. Then, we validate item loadings, reliability, and validity. Finally, we present and discuss the results of the hypothesis testing.

\subsection{Descriptive statistics}

Our call for participation reached 85 Frenchspeaking students and 14 English-speaking students from a population of 890 students enrolled in the course, which gave a response rate of $11.12 \%$.

We used SPSS software for descriptive statistics. There were slightly more female $(56.6 \%)$ than male (43\%) students. Most of the respondents were between 21 and 25 years old $(89.9 \%)$. Almost all the students were enrolled in campuses located in France $(52.5 \%$ in Sophia Antipolis, 33.3\% in Lille, and 13\% in Paris). All the students, except one, had at least 5 years of experience using computers. Because the course was compulsory for most of the students and was offered in a classroom, more than two thirds of the sample (72.8\%) attended at least eight classroom sessions out of ten. More than half of the students used at least one of the five modules of the PairForm system for the course $(58.6 \%)$. We recall that using these modules was not required.
As can be seen in Table 1, age and experience variances were near 0 . Thus, we deemed it necessary to remove them from subsequent analyses because of the potential to bias regression results.

Table 1. Descriptive statistics for one-item constructs

\begin{tabular}{l|r|r|r|r}
\multirow{2}{*}{ Constructs } & & Mean & Std. Deviation & Variance \\
\hline Gender & & 1.565 & .498 & .248 \\
\hline Age & & 2.080 & .308 & .095 \\
\hline Experience & & 4.969 & .301 & .091 \\
\hline Classroom presence & & 8.050 & 2.205 & 4.865 \\
\hline PairForm use & & 1.767 & 1.845 & 3.405 \\
\hline Valid sample & 99 & & &
\end{tabular}

\subsection{Item loadings and reliability}

We used confirmatory factor analysis to assess the validity of the measurement instruments. As can be seen in Table 2 (except for the "Anxiety" construct, which lost four items), all the remaining items had significant and strong loading values, exceeding 0.5 , as recommended by Hair et al. [34].

We tested the internal consistency with two coefficients: the Cronbach's alpha obtained from the SPSS software and the composite reliability (CR) after running the Smart-PLS software. As shown in Table 2, the values of the alphas for all the measurement instruments were satisfactory, exceeding 0.7 as recommended by Nunnally [35]. Tables 2 also shows that the measurement instruments of the endogenous variables fulfilled the recommended level of $\mathrm{CR}$, exceeding the recommended 0.7 [36].

Table 2. Item loadings, Cronbach's alpha, and composite reliability

\begin{tabular}{|c|c|c|c|c|c|}
\hline Variable & Item & Ld. & Variable & Item & Ld. \\
\hline \multirow[t]{10}{*}{$\begin{array}{l}\text { Performance } \\
\text { expectancy }\end{array}$} & \multicolumn{2}{|c|}{$\begin{array}{l}\alpha=.977 \\
\mathrm{CR}=.980\end{array}$} & \multirow[t]{4}{*}{$\begin{array}{l}\text { Behavioral } \\
\text { intention }\end{array}$} & \multicolumn{2}{|c|}{$\begin{array}{l}\alpha=.954 \\
\mathrm{CR}=.970\end{array}$} \\
\hline & PE1 & .941 & & BI1 & .953 \\
\hline & PE2 & .948 & & BI2 & .947 \\
\hline & PE3 & .911 & & $\mathrm{BI} 3$ & .973 \\
\hline & PE4 & .947 & \multirow[t]{8}{*}{ Anxiety } & \multirow{2}{*}{\multicolumn{2}{|c|}{$\begin{array}{l}\alpha=.967 \\
\mathrm{CR}=.972\end{array}$}} \\
\hline & PE5 & .886 & & & \\
\hline & PE6 & 908 & & Anx2 & .837 \\
\hline & PE7 & 926 & & Anx4 & .947 \\
\hline & PE8 & 932 & & Anx 5 & .894 \\
\hline & PE9 & 871 & & Anx7 & .952 \\
\hline \multirow{5}{*}{$\begin{array}{l}\text { Effort } \\
\text { expectancy }\end{array}$} & \multirow{2}{*}{\multicolumn{2}{|c|}{$\begin{array}{l}\alpha=.958 \\
\mathrm{CR}=.972\end{array}$}} & & Anx 8 & .915 \\
\hline & & & & Anx9 & .929 \\
\hline & EE1 & .955 & \multirow[t]{6}{*}{ Autonomy } & \multirow{2}{*}{\multicolumn{2}{|c|}{$\begin{array}{l}\alpha=.929 \\
\mathrm{CR}=.947\end{array}$}} \\
\hline & EE2 & .952 & & & \\
\hline & EE3 & .975 & & Aut1 & .795 \\
\hline \multirow{3}{*}{$\begin{array}{l}\text { Social } \\
\text { influence }\end{array}$} & \multirow{2}{*}{\multicolumn{2}{|c|}{$\begin{array}{l}\alpha=.932 \\
C R=.943\end{array}$}} & & Aut2 & .909 \\
\hline & & & & Aut3 & .865 \\
\hline & SI1 & .846 & & Aut4 & .816 \\
\hline
\end{tabular}




\begin{tabular}{|c|c|c|c|c|c|}
\hline & SI2 & .806 & & Aut5 & .885 \\
\hline & SI3 & .845 & \multirow{15}{*}{ Attitude } & Aut6 & .920 \\
\hline & SI4 & .776 & & \multirow{2}{*}{\multicolumn{2}{|c|}{$\begin{array}{l}\alpha=.952 \\
\mathrm{CR}=.964\end{array}$}} \\
\hline & SI5 & .608 & & & \\
\hline & SI6 & .792 & & & .931 \\
\hline & SI7 & .883 & & Att2 & .940 \\
\hline & SI8 & .852 & & Att3 & .942 \\
\hline & SI9 & .833 & & Att4 & .944 \\
\hline \multirow[t]{8}{*}{$\begin{array}{l}\text { Facilitating } \\
\text { conditions }\end{array}$} & \multicolumn{2}{|c|}{$\begin{array}{l}\alpha=.930 \\
\mathrm{CR}=.943\end{array}$} & & Att5 & .832 \\
\hline & FC1 & .845 & & & \\
\hline & $\mathrm{FC} 2$ & .843 & & & \\
\hline & $\mathrm{FC} 3$ & .797 & & & \\
\hline & FC4 & .819 & & & \\
\hline & $\overline{\text { FC5 }}$ & .856 & & & \\
\hline & FC6 & .895 & & & \\
\hline & FC7 & .820 & & & \\
\hline
\end{tabular}

$\alpha$ : Cronbach's alpha; CR: Composite reliability (Rho); Ld.: Outer loadings

\subsection{Convergent and discriminant validity}

We used the average variance extracted (AVE) measure to assess the convergent validity. The AVE measure allows for the assertion that items that theoretically measure the same variable are correlated. As can be seen in Table 3, all the AVEs of the latent variables were greater than 0.5 , as suggested by Chin [37], which ensures the convergent validity of the measurement instruments.

Discriminant validity is ensured when the square roots of the AVEs are greater than the other correlations [38]. This helps to ensure that items that theoretically belong to different variables are not correlated. We can confirm discriminant validity because the square roots of the AVEs were greater than all the other correlations on a same column for each endogenous variable (Table 3 ).

Table 3. Convergent and discriminant validity for latent variables

\begin{tabular}{l|c|c|c|c|c|c|c|c|c} 
Variables & AVE & 1 & 2 & 3 & 4 & \multicolumn{1}{c}{5} & 6 & 7 & 8 \\
\hline 1. Anxiety & .832 & $\mathbf{. 9 1 2}$ & 0 & 0 & 0 & 0 & 0 & 0 & 0 \\
\hline 2. Attitude & .843 & .247 & $\mathbf{. 9 1 8}$ & 0 & 0 & 0 & 0 & 0 & 0 \\
\hline 3. Autonomy & .749 & .088 & .295 & $\mathbf{. 8 6 5}$ & 0 & 0 & 0 & 0 & 0 \\
\hline 4. BI & .917 & .239 & .744 & .270 & $\mathbf{. 9 5 7}$ & 0 & 0 & 0 & 0 \\
\hline 5. EE & .922 & .183 & .650 & .229 & .463 & $\mathbf{. 9 6 0}$ & 0 & 0 & 0 \\
\hline 6. FC & .704 & .212 & .758 & .270 & .680 & .735 & $\mathbf{. 8 3 9}$ & 0 & 0 \\
\hline 7. PE & .844 & .287 & .860 & .318 & .666 & .687 & .771 & $\mathbf{. 9 1 8}$ & 0 \\
\hline 8. SI & .651 & .568 & .731 & .123 & .651 & .642 & .712 & .742 & $\mathbf{. 8 0 6}$ \\
Diagonal elements: square roots of AVEs; Off-diagonal \\
elements: correlations
\end{tabular}

\subsection{Hypothesis testing}

Table 4 shows that three of the 15 tested hypotheses were confirmed (in bold characters). We recall that the age and experience did not play a moderating role because their variances were almost null.

Table 4. Structural model results

\begin{tabular}{|c|c|c|c|c|c|}
\hline \multirow[t]{2}{*}{ Hypotheses } & \multirow{2}{*}{$\begin{array}{c}\begin{array}{c}\text { Dependent } \\
\text { variables }\end{array} \\
\begin{array}{c}\text { Independent } \\
\text { variables }\end{array} \\
\end{array}$} & \multicolumn{2}{|c|}{$\begin{array}{c}\text { Behavioral } \\
\text { intention } \\
\mathrm{R}^{2}=.640\end{array}$} & \multicolumn{2}{|c|}{$\begin{array}{c}\text { Use behavior } \\
\mathrm{R}^{2}=.289\end{array}$} \\
\hline & & $\boldsymbol{\beta}$ & $\mathbf{t}$ & $\beta$ & $\mathbf{t}$ \\
\hline $\mathrm{H}_{1}$ & $\mathrm{PE}$ & -.189 & .360 & & \\
\hline $\mathrm{H}_{2}$ & $\mathrm{EE}$ & -.185 & .363 & & \\
\hline $\mathrm{H}_{3}$ & SI & .371 & .701 & & \\
\hline $\mathbf{H}_{4-} \mathrm{H}_{5}$ & FC & .292 & $2.035^{* *}$ & .490 & $3.962^{* * *}$ \\
\hline $\mathrm{H}_{6}$ & BI & & & -.062 & 0.519 \\
\hline $\mathrm{H}_{7}-\mathrm{H}_{8}$ & Autonomy & .085 & 0.864 & .081 & .924 \\
\hline $\mathrm{H}_{9}-\mathrm{H}_{10}$ & Anxiety & -.055 & .526 & -.107 & 1.143 \\
\hline $\mathbf{H}_{\mathbf{1 1}}-\mathrm{H}_{12}$ & Attitude & .479 & $2.562^{* * *}$ & .094 & .623 \\
\hline $\mathrm{H}_{1 \mathrm{a}}$ & $\mathrm{PE} *$ Gender & .064 & 0.073 & & \\
\hline $\mathrm{H}_{2 \mathrm{a}}$ & EE * Gender & -.1 & 0.363 & & \\
\hline $\mathrm{H}_{3 \mathrm{a}}$ & SI * Gender & -.102 & 0.112 & & \\
\hline $\mathrm{H}_{5 \mathrm{a}}$ & $\begin{array}{l}\text { FC*Age } \\
* \text { Experience }\end{array}$ & & & \multicolumn{2}{|c|}{ Not tested } \\
\hline
\end{tabular}

$\beta$ : Path coefficient; $t$ : Statistic for significance; One-tailed test; Degree of freedom $=98$

$* \mathrm{t}$ value $>1.29$ (Confidence interval $=90 \%)$

$* *$ t value $>1.66($ Confidence interval $=95 \%)$

$* * * \mathrm{t}$ value $>2.36$ (Confidence interval $=99 \%)$

The path coefficient of the relationship between facilitating conditions and behavioral intention is significant and positive $(\beta=0.292, \mathrm{t}=2.035, \mathrm{p}<0.05)$, lending support $\mathrm{H}_{4}$. We can thus assert that the availability of facilitating conditions may make students more willing to use PairForm. This result corroborates those of Venkatesh et al. [25], who found a significant and positive relationship between facilitating conditions and behavioral intentions in a consumer context. Taiwo and Downe [39] reported studies that found facilitating conditions a significant predictor of intention [40-42].

The effect of facilitating conditions on use behavior is positive $(\beta=0.490)$ and significant $(t=3.962, p<$ 0.01). This result supports $\mathrm{H}_{5}$. Thus, the more facilitating conditions are present, the more students will use PairForm. This result is consistent with those of Venkatesh et al. [23], who found a direct and positive influence of facilitating conditions on usage. Venkatesh et al. [25] also confirmed the positive and significant direct relationship between facilitating conditions and use while testing an extended version of the UTAUT model.

Facilitating conditions are technological, informational, and human resources that help to remove barriers to using PairForm. Because all courses must be given in the classroom, we believe 
technological resources in the Skema Business School are relatively limited, which made the facilitating conditions more likely to affect adoption as compared to the other variables. Consequently, whether they intend to use the technology or actually use it, students need to know that support is available to help them with their learning. Managers at higher learning institutions can rely on this result to justify investments in the human, informational, and technological resources required to encourage students to use PairForm. These resources could include user manuals about PairForm, an online FAQ, discussion forums, training sessions, or personal human support.

The effect of attitude on behavioral intention was positive $(\beta=.479)$ and significant $(\mathrm{t}=2.562, \mathrm{p}<0.01)$. $\mathrm{H}_{11}$, which states a better attitude among students might make them more willing to use PairForm, is thus confirmed. This result is supported by previous theories that consider attitude to be a strong and significant antecedent of the intention to use and the effective use of technology [43]. Like in Thomas et al. [44], we found attitude has the largest effect on behavioral intentions. The same authors stated that, by improving facilitating conditions, we can already boost attitude toward technology. However, we suggest it is a wasted investment to offer students the best conditions for technology use if their attitude toward that technology is negative. Managers and instructors at higher learning institutions have to take specific actions to improve students' attitudes toward technology to foster adoption. In the case of the Skema Business School, they have to adapt the School's strategy to embrace the new context of technology use in education. For instance, the School could focus on the use of a variety of technologies in classroom courses (e.g., electronic polls, online evaluations, etc.). The School could also adopt a blended learning formula for some courses using webinar software, such as Adobe Connect. This last suggestion could be a winning strategy for budget savings because a single instructor could teach the same information systems course, which is offered at different times on various campuses during the same semester, with a webinar system.

\section{Conclusion}

We conclude this paper with a summary of the results and contributions of the study. Then, we discuss some limitations with the study and avenues for future research.

\subsection{Results and contributions}

The aim of this research was to identify the determinants of the behavioral intention to use and the use behavior of the social learning system PairForm by students at the Skema Business School. Results show that facilitating conditions and attitudes were the main determinants of the behavioral intention, and only facilitating conditions were able to explain the use behavior.

The theoretical contribution of this research is our attempt to enrich technology adoption literature by testing the UTAUT model in the special context of using a LMS for social learning. Our findings provide a better understanding of the adoption and the acceptance of social learning technologies in the context of a multi-campus course.

Another contribution of this research is the finding that facilitating conditions and attitude are the most important predictors of behavioral intention as they explain $63 \%$ of the variance of the behavioral intention variable. We consider the explained variance of behavioral intention to be high because it is approaching $70 \%$ of Venkatesh et al.'s [23] results. Thomas et al. [44] found similar results, asserting that facilitating conditions and attitudes are the most important predictors of behavioral intention to use mobile learning in higher education in Guyana. However, Thomas et al. posited the results of the studies from non-Western countries would be different, by suggesting the difference between their results and those of Venkatesh et al. [23] was due to the countries' level of development (developed vs. developing countries). We disagree with this last assertion because our results show that the explaining variables of the UTAUT model behave the same way in developed countries (e.g., the results of our study) as in developing countries (e.g., the results of the study by Thomas et al. [44]). We are convinced that the difference is due more to the extent to which the school considers technology in its learning strategy rather than due to technological development of the host country.

The explained variance of use behavior was $28.9 \%$ and was explained only by the facilitating conditions variable. In this regard, students seem to be saying they did not use PairForm because the resources to help them use it were not available. At the outset, we hypothesized that personal characteristics, such as autonomy, anxiety, and attitude, would explain use behavior. However, this was not the case because even if most of the students were enrolled in the same school, they were spread across four towns and came from different countries. Therefore, in a context of a heterogeneous sample, we were not able to control for personal characteristics when explaining use behavior, 
which led to low explained variance of this last variable.

In light of these results, we recommend the Skema Business School work on improving students' attitude toward the use of learning technologies, especially social learning technologies, for education. We also suggest the School offer more facilitating conditions to students to strengthen the adoption of a LMS with social media. As previously suggested, the Skema Business School can first adopt webinar systems and then integrate social learning systems to gradually accustom students to using technology in their courses. This can be a winning strategy for both the schooldue to the savings that it can offer - and the students who can enhance their learning and results.

\subsection{Limitations and future research}

The main limit of this research is the sample size. Although two reminders were sent to students inviting them fill in the questionnaire, less than 100 students accepted. This result can be explained by the fact that messages were sent to them from the course owner, who was mostly unknown to most students. Moreover, students were not engaged in using social media for their learning because only their physical classroom presence was compulsory and counted toward their assessments. Therefore, students were not encouraged to extract the maximum benefit from social learning. The few of them who used the social learning system participated to our survey.

For factorial analysis, Onwuegbuzie and Daniel [45] suggest a sample size of at least 5 times the number of variables. For multivariate analysis, Hair et al. [46] recommended a ratio of 10 responses per variable to ensure a minimal statistical power. In prior research, a minimum sample size of 100 was considered sufficient to carry out path modeling [47]. For this study, the first suggestion was respected, but the second or third recommendations were not because 100-110 responses would have been necessary for a statistical power. However, the use of Smart-PLS software allowed mitigation of this limit because partial least squares for structural equation modeling are often recommended for small samples [48].

We recommend that future research replicate this study, examining the same research model but with a larger sample. The use of social media for learning has a great potential and is not likely to fade away. Technology natives are changing the education landscape, and social media are some of the actors in this change. Moreover, LMSs that have a social media component integrated in them are scarce. We deem it interesting to investigate further how students accept and adopt this new variant of learning delivery.

\section{References}

[1] Prensky, Digital natives, digital immigrants. On the Horizon, 2001. 9(5): p. 1-6.

[2] Unit, E.I., The Future of Higher Education: How Technology Will Shape Learning, N.M. Consortium, Editor. 2008.

[3] Kim, K.J. and B. C.J., The future of online teaching and learning in higher education: The survey says... EDUCAUSE Quarterly, 2006. 4: p. 22-30.

[4] Bandura, A., Social learning theory. 1977: New York: General Learning Press.

[5] Raspopovic, M., et al., The effects of integrating social learning environment with online learning. International Review of Research in Open and Distributed Learning, 2017. 18(1): p. 141-160.

[6] Popescu, E. and D. Cioiu, eMUSE - Integrating Web 2.0 Tools in a Social Learning Environment, in International Conference on Web-Based Learning. 2011: Hong Kong, China. p. 1-10.

[7] Bonafous, E., et al., Le Social Learning, M. Juganaikloo and L. Barbaritm, Editors. 2018, IMT Atlantique: Bretagne, France. p. 1-61.

[8] Lakhal, S., H. Khechine, and D. Pascot, Student behavioural intentions to use desktop video conferencing in a distance course: Integration of autonomy to the UTAUT model. Journal of Computing in Higher Education, 2013. 25(2): p. 93-121.

[9] Khechine, H. and S. Lakhal, Technology as a doubleedged sword: From behavior prediction with UTAUT to students' outcomes considering personal characteristics. Journal of Information Technology Education: Research, 2018.

[10] Taylor, S. and P.A. Todd, Understanding information technology usage: A test of competing models. Information Systems Research, 1995. 6(2): p. 144-176.

[11] Langley, A. Experiential learning, e-learning and social learning: The EES approach to developing blended learning. in The Fourth Education in a Changing Environment Conference Book 2007. Santa Rosa, California: Informing Science Press.

[12] Vaughan, N.D., M. Cleveland-Innes, and R.D. Garrison, Teaching in Blended Learning Environments: Creating and Sustaining Communities of Inquiry. Issues in Distance Education, ed. T.A.a.D. Wiley. 2013, Athabasca University, Edmonton: Au Press. 142.

[13] Scenari, A. Portail de la communauté Scénari. 2018 May 16th 2018]; Available from: https://scenari.org/.

[14] PairForm. Démarrer avec PairForm-Web. 2018; Available from: https://www.pairform.fr/doc/24/1/92/web/co/presentationgenerale.html.

[15] Moghavvemi, S., et al., Social media as a complementary learning tool for teaching and learning: The case of youtube. International Journal of Management Education, 2018. 16(1): p. 37-42.

[16] Platon, O.E., C.-N. Caranica, and A. Catana, Social media tools used for teaching and learning in the higher education system, in The 14th International Scientific 
Conference eLearning and Software for Education. 2018: Bucharest. p. 453-456.

[17] Khechine, H., P. Ndjambou, and S. Lakhal, A metaanalysis of the UTAUT model: 11 years later. Canadian Journal of Administrative Sciences, 2016. 33(2): p. 138-152. [18] Alawadhi, S. and A. Morris, The use of the UTAUT model in the adoption of e-government services in Kuwait, in Proceedings of the 41st Annual Hawaii International Conference on System Sciences. 2008: Hawaii. p. 1-11.

[19] Khechine, H., et al., UTAUT model for blended learning: The role of gender and age in the intention to use Webinars. Interdisciplinary Journal of E-Learning and Learning Objects, 2014. 10(1): p. 33-52.

[20] Ima, I., Y. Kimb, and H.J. Hanc, The effects of perceived risk and technology type on users' acceptance of technologies. Information \& Management, 2008. 45(1): p. 19.

[21] Olatubosun, O., F. Olusoga, and A.P. Shemi, Direct determinants of user acceptance and usage behavior of eLearning system in Nigerian tertiary institution of learning. Journal of Information Technology and Economic Development, 2014. 5(2): p. 95-111.

[22] Lakhal, S. and H. Khechine, Relating personality (Big Five) to the core constructs of the Unified Theory of Acceptance and Use of Technology. Journal of Computers in Education, 2017. 4(3): p. 251-282.

[23] Venkatesh, V., et al., User acceptance of information technology: Towards a unified view. MIS Quarterly, 2003. 27(3): p. 425-478.

[24] Venkatesh, V. and M.G. Morris, Why don't men ever stop to ask for directions? Gender, social influence, and their role in technology acceptance and usage behavior. MIS Quarterly, 2000. 24(1): p. 115-139.

[25] Venkatesh, V., J.Y.L. Thong, and X. Xu, Consumer acceptance and use of information technology: Extending the unified theory of acceptance and use of technology. MIS Quarterly, 2012. 36(1): p. 157-178.

[26] Celik, H., Customer online shopping anxiety within the unified theory of acceptance and use technology (UTAUT) framework. Asia Pacific Journal of Marketing and Logistics, 2016. 28(2): p. 278-307.

[27] Alba, J.W. and J.W. Hutchinson, Dimensions of consumer expertise. Journal of Consumer Research, 1987. 13(4): p. 411-454.

[28] Johns, G., The essential impact of context on organizational behavior. Academy of Management Review, 2006. 31(2): p. 386-408.

[29] Bozionelos, N., Socio-economic background and computer use: the role of computer anxiety and computer experience in their relationship. International Journal of Human-Computer Studies, 2004. 61(5): p. 725-746.

[30] Barnett, T., et al., Measuring system usage: Replication and extensions. Journal of Computer Information Systems, 2007. 47(2): p. 76-85.

[31] AbuShanab, E., J.M. Pearson, and A. Setterstrom, Internet banking and customers' acceptance in Jordan: The unified model's perspective. Communications of the Association for Information Systems, 2010. 26(1): p. 493524.

[32] El-Gayar, O., M. Moran, and M. Hawkes, Students' acceptance of tablet PCs and implications for educational institutions. Educational Technology \& Society, 2011. 14(2): p. 58-70.

[33] Fillion, G., L'intégration des TIC dans la formation universitaire : Une étude des résultats éducationnels des étudiants dans les contextes de présence et de non présence en classe, in MIS Department. 2005, Laval University: Quebec, Canada.

[34] Hair, J.F.J., et al., Multivariate data analysis with readings, ed. E. Cliffs. 1995, New jersey: Prentice Hall College Div. (4th édition). 757.

[35] Nunnally, J.C., Psychometric theory, 2nd edition, ed. McGraw-Hill. 1978, New York. 701.

[36] Gerbing, D.W. and J.C. Anderson, An updated paradigm for scale development incorporating unidimensionality and its assessment. Journal of Marketing Research, 1988. 25(2): p. 186-192.

[37] Chin, W., The partial least squares approach to structural equation modeling, in Modern Methods for Business Research, G.A. Marcoulides, Editor. 1998, Lawrence Erlbaum Associates: London. p. 295-336.

[38] Fornell, C. and D.F. Larcker, Evaluating structural equation models with unobservable variables and measurement error. Journal of Marketing Research, 1981. 18(1): p. 39-50.

[39] Taiwo, A.A. and A.G. Downe, The theory of user acceptance and use of technology (UTAUT): A meta-analytic review of empirical findings. Journal of Theoretical and Applied Information Technology, 2013. 49(1): p. 48-58.

[40] Foon, Y.S. and B.C.Y. Fah, Internet banking adoption in Kuala Lumpur: An application of UTAUT model. International Journal of Business and Management, 2011. 6(4): p. 161-167.

[41] Venkatesh, V., T.A. Sykes, and X. Zhang. Just what the doctor ordered: A revised UTAUT for EMR system adoption and use by doctors. in 44th Hawaii International Conference on System Sciences. 2011.

[42] Venkatesh, V., X. Zhang, and T.A. Sykes, Doctors do too little technology: A longitudinal field study of an electronic healthcare. Journal Information Systems Research, 2011. 22(3): p. 523-546.

[43] Davis, F.D., Perceived usefulness, perceived ease of use, and user acceptance of information technology. MIS Quarterly, 1989. 13(3): p. 319-339.

[44] Thomas, T.D., L. Singh, and K. Gaffar, The utility of the UTAUT model in explaining mobile learning adoption in higher education in Guyana. International Journal of Education and Development using Information and Communication Technology, 2013. 9(3): p. 71-87.

[45] Onwuegbuzie, A.J. and L.G. Daniel, Typology of analytical and interpretational errors in quantitative and qualitative educational research. Current Issues in Education, 2003. 6(2): p. 1-34.

[46] Hair, J.F.J., et al., Multivariate Data Analysis (5th ed), ed. P.-H. International. 1998: Upper Saddle River.

[47] Hoyle, R.H., Structural Equation Modeling, ed. T. Oaks. 1995, California: AGE Publications, Inc.

[48] Wong, K.K.-K., Partial least squares structural equation modeling (PLS-SEM) Techniques using SmartPLS. Marketing Bulletin, 2013. 24(1): p. 1-32. 